\title{
CLEANING PICTORIAL HERITAGEMANAGEMENT AND DISSEMINATION OF CLEANING RECORDS AND STRATIGRAPHIC DATA
}

\author{
J. M. Barros García a*, C. M. Guillén Juan b \\ a Instituto Universitario de Restauración del Patrimonio, Universitat Politècnica de València, Camino de Vera s/n, 46022 Valencia, \\ Spain - jobargar@crbc.upv.es \\ b Art conservator, c/ soledad, 36 Benejuzar (Alicante) Spain - claguiju@bbaa.upv.es
}

KEY WORDS:Cleaning, painting, documentation, archaeology, stratigraphy, database, stratigraphic unit, solubility test, matrix

\begin{abstract}
:
At present, the process of documentation can be considered the cornerstone of the different tasks within the field of conservation and restoration of cultural heritage. However, this is not the case with cleaning. Despite its importance in the conservation of pictorial heritage, little effort has been made to improve the management and dissemination of information. Cleaning is one of the most usual procedures, yet, at the same time, it is also one of the most problematic and controversial. Therefore, it would be very useful that the information generated by cleaning could be widely disseminated and serve as reference for researchers and conservators around the world. When a conservator carries out a cleaning operation on a painting, two kinds of interrelated data are produced: stratigraphic data and cleaning records. Stratigraphic data are those concerning the configuration and composition of the stratigraphic structure on which the cleaning is carried out. Cleaning records gather together data concerning the actual cleaning process. All this information is key for conservators when working on other paintings. The information published is usually insufficient to understand how the intervention was carried out, so there is a need for standardized systems which allow a great deal of information to be gathered and disseminated with ease. This paper explains a selection of proposals, some of which are already in use, and others which are being developed: stratigraphic unit recording sheets, solubility test recording sheets and stratigraphic diagrams.
\end{abstract}

\section{INTRODUCTION}

Nowadays, at a time when important changes are influencing the field of conservation and restoration of cultural heritage, a number of questions must be posed concerning how to continue working in order to conserve pictorial heritage. One of these questions is: How can the way conservators work on cleaning, a complex and controversial procedure, be improved?

Innovation in this field has been evolving in the last decades through the development of new cleaning systems. In fact, any other line of work has been eclipsed by the impressive advances achieved by researchers such as Richard Wolbers (2000). Lack of interest towards other possibilities of innovation in cleaning, of attaining significant progress, has been enforced by the complete failure in trying to establish a "theory" of cleaning and subsequent attempts have all led to dead ends. Therefore, it is hardly surprising that researchers have clung to lines of work which, at least, allow progress towards a clear aim: designing new cleaning systems which permit work to be carried out in a more effective manner, while, at the same time, being safer for the work and the conservator.

The aim of this text is to show that there is another line of investigation which can also provide significant results in development and innovation within the field of cleaning pictorial heritage. The proposed line of investigation involves applying the work and documentation methodology used in archaeological stratigraphy. Although this methodology was developed in and for archaeological excavations, it can be applied to any kind of stratigraphic structures, including pictorial ones. Among the main advantages of this methodology when applied to cleaning are that it allows a greater amount of information to be generated, and also to develop solutions in order to attain a better dissemination of the data obtained.
Management and dissemination of information is a key matter in the innovation of cleaning, just as it is in any other field of investigation. The usefulness of the information lies in its reaching the largest possible number of researchers and conservators. So, in order to comply with this requirement, the use of different resources developed by archaeologists, such as stratigraphic unit recording sheets and stratigraphic diagrams, becomes of utmost importance.

\section{ARCHAEOLOGICAL STRATIGRAPHY AND CLEANING}

In the 1960s, archaeology started to evolve towards new techniques of excavation and documentation. The works of Barker (1977) and Harris (1989) put forward a more complete view of how an excavation should be carried out. On what principles was this archaeological methodology based? The basic principle was very simple: to decompose a structure into its essential elements, in such a way that the actions which had created it were revealed.

The essential elements are the stratigraphic units (SU), which can be positive (strata) or negative (losses). The units must be recorded as they are identified, starting with the more recent ones and working towards the older ones. This means that each layer is identified, studied and completely excavated before starting on the next one. Thus, the site's structure is "dismantled" in an inverse order to its creation. If the documentation obtained is sufficiently complete and rigorous, it is possible to "virtually" reconstruct the site with all its units, to understand the relationships among them and to establish absolute chronologies, or at least, relative ones (Roskams, 2001). 
When these concepts are revised, the similarities between archaeological methodology and cleaning methodology become obvious. In the latter, a series of strata, which are studied and recorded, are also progressively removed (Figure 1).

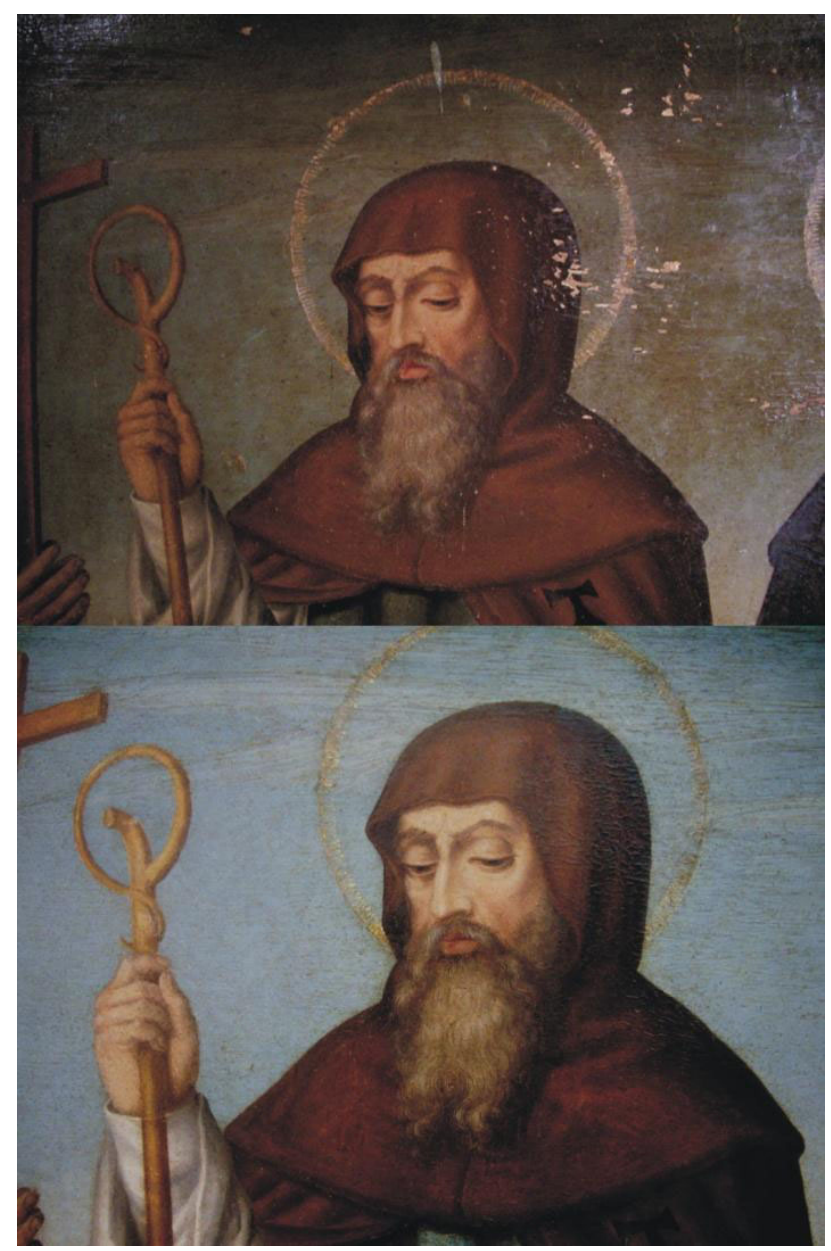

Figure 1: Detail of a cleaning process. Saint Anthony of Padua with Saint Anthony Abbot and Saint Nicholas of Tolentino, anonymous artist (16th century), Convent of Santa Clara, Gandia.

Apart from general similarities, it is interesting to note that the tools used by archaeologists in the recording process can also be used by conservators. This has become more than obvious in the last decade, thanks to several papers. Watts et al. published in 2002 "The power of the matrix: the application of archaeological stratigraphy to the interpretation of complex paintings". The "matrix" is a flow diagram developed by the archaeologist Edward C. Harris in the 1970s, as a way of showing in a two-dimensional document the whole complexity of the interrelationships among units in an archaeological excavation. A few decades later, the "matrix" or stratigraphic diagram became an essential element in the stratigraphic study of an archaeological site, a building (Doglioni, 1997) or even an archaeological object (Vidale and Proença de Almeida, 2001). Figure 2 shows how the different units are organized in the diagram according to relative chronology (the oldest at the bottom and the more modern on top) and connected according to the relationships among them: for example, a direct connection by means of a line implies superposition (Barros García, 2004). The great advantage with this kind of diagram is that the information can be processed with different types of software programs, thus allowing multiple operations to be carried out.

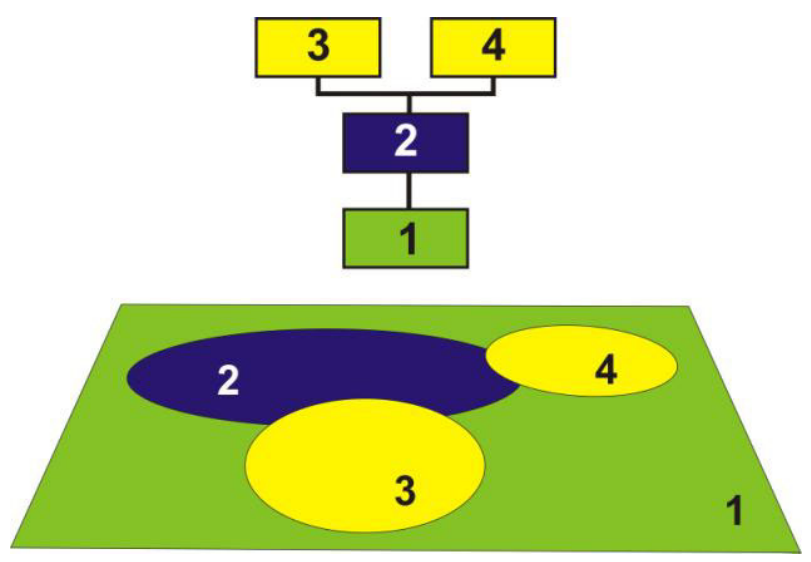

Figure 2: SU are organized in the diagram according to relative chronology and connected according to the relationships among them.

Prisco et al. (2004) have shown how the stratigraphic diagram can be applied to the study of the evolution of a wall painting. Shortly after, other works have developed the idea of applying archaeological methodology more specifically to cleaning, and indeed, using the SU recording sheet as the central element in the recording process (Barros García, 2009). In the recording sheet, all the information relevant to a stratigraphic unit is gathered together.

An "archaeological" orientation in the cleaning of paintings carries some noteworthy advantages concerning the possibility of innovation in the long term. It is a way of working which breaks with the aesthetic enslavement of the cleaning process while introducing a new paradigm: cleaning as a means of obtaining information, as an analytic process in itself. Firstly, it makes the conservator observe more rigorously the different strata and their relationships during the cleaning process and compels him towards a logical approach to complicated stratigraphic situations. Secondly, (and this is the aspect which will be dealt with here), it generates a great deal of extremely detailed information concerning the stratigraphic structure (made up of non-original strata) and the cleaning itself. Such detailed documentation, can in itself, be a very valuable resource with regard to research. One of the most interesting aspects is the creation of stratigraphic structure databases. This would permit, for example, comparative studies to be carried out between different restoration interventions.

A complete and comprehensive documentation allows a better analysis of the whole decision-making process in such a complex operation. Furthermore, as structures are compared before and after the intervention, it allows all the stratigraphic changes caused by the restoration process itself to be studied more accurately. In short, it means being able to expand the possibility of innovation, of advancing in a field of research in which there is still a great deal to do if we indeed aspire to attain something we can call, with propriety, "cleaning methodology". 


\section{CLEANING RECORDS AND STRATIGRAPHIC DATA}

At present, the process of documentation can be considered the cornerstone of the different tasks within the field of conservation and restoration of cultural heritage. With the development of all kinds of software programs and the Internet, it is possible to create databases, to elaborate virtual reconstructions, etc.

Archaeology and architecture are two fields which are making the most of these resources with great success. Unfortunately, in the conservation of pictorial heritage, this is not so. The case of cleaning is a clear example. It is one of the most frequent procedures, while, at the same time, it is one of the most problematic and controversial. Therefore, it would be extremely useful if, during cleaning, a great amount of information could be generated which, in turn, could be widely disseminated and serve as reference for researchers and conservators around the world. When a conservator carries out a cleaning operation on a painting, two kinds of interrelated data are produced: stratigraphic data and cleaning records.

Stratigraphic data are those concerning the configuration and composition of the stratigraphic structure on which the cleaning is carried out. Some of that information can be obtained before the actual cleaning process is carried out, but some more information can also be obtained during cleaning. When a stratum is removed (for example, an overpaint) new strata, which were not visible before, may appear (for example, fillers or new overpaints).

Cleaning records gather together data regarding the actual process of cleaning, such as, among others, strata removed, solubility tests, cleaning techniques used and results obtained. This kind of information is relatively habitual (although it is not usually very complete) in specialized literature but it is practically impossible to find in the Internet. Despite the fact that these data are very useful for all conservators, there seems to be no particular interest in disseminating them. Insofar as stratigraphic information is concerned, this can be found more easily, but it tends to be limited to cross-sections.

Cleaning is a process which is essentially concerned with subtle details: very thin strata which are hardly visible, numerous sensitive decisions made throughout the whole process, etc. All this information is fundamental for conservators when working on other paintings. The information which is usually published is just not enough in order to understand how the intervention was carried out, so there is a need for standardized systems which allow a great deal of information to be gathered more accurately and disseminated with ease.

The following sections explain a selection of proposals, some of which are already in use, and others which are being developed: SU recording sheets, solubility test recording sheets and stratigraphic diagrams.

\section{STRATIGRAPHIC WIT RECORDING SHEETS}

During the cleaning process, each stratum (positive SU) and each loss (negative SU) is numbered and recorded separately on a SU recording sheet. Thus, data regarding their physicalchemical characteristics (colour, texture, hardness, composition, etc.), their location (situation on the horizontal level) and their relationships with the other units (situation in the stratigraphic sequence), are gathered together (Barros García, 2009).
Figure 3 shows both parts of this kind of sheet, adapted to document the cleaning process. This model has already been used, with very good results, in order to record the cleaning of several paintings (Barros García, 2009; Barros García and Pérez Marín, 2010). In addition to the SU's characteristics, the recording sheet also gathers some data concerning the cleaning, for example, how the stratum was removed. An important step in improving the recording system is to combine SU recording sheets with solubility test recording sheets.

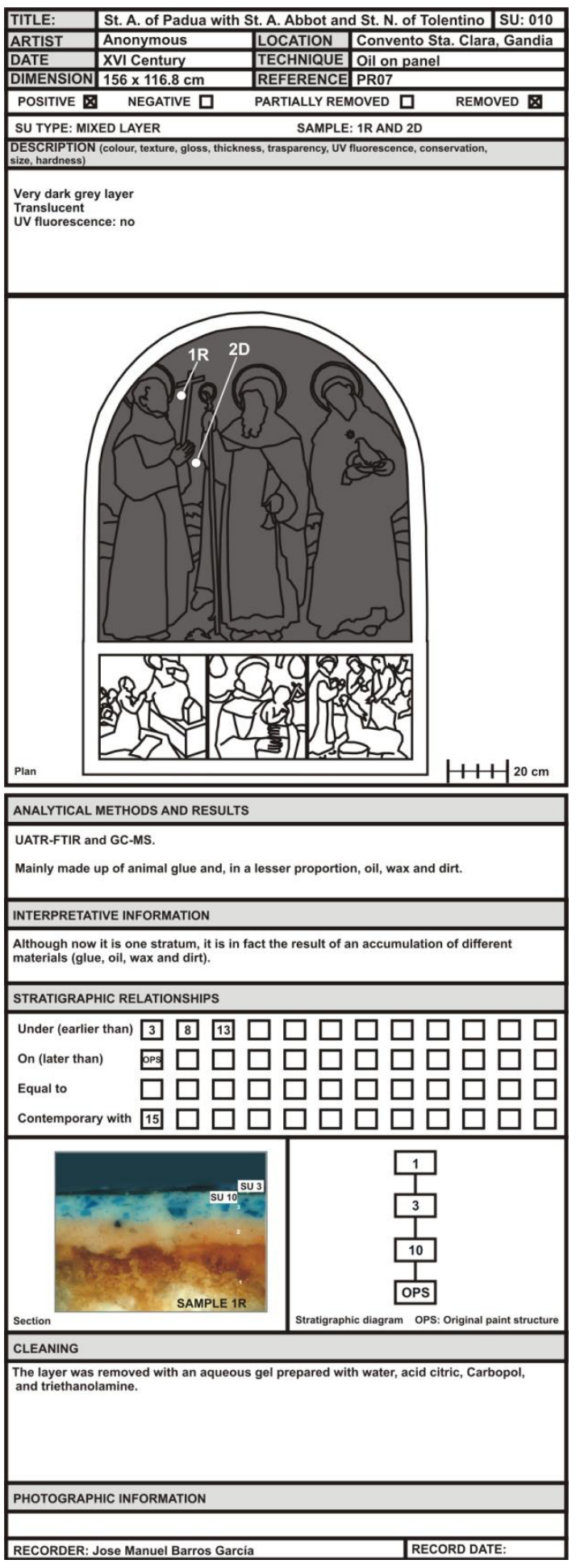

Figure 3: SU recording sheet 10 of Saint Anthony of Padua with Saint Anthony Abbot and Saint Nicholas of Tolentino. 


\section{SOLUBLITY TEST RECORDING SHEETS}

A clear example of the limitations inherent to the systems of documentation used at present in cleaning can be found in solubility test (ST) recording sheets. Solubility tests are usually carried out in order to study the solubility of the non-original strata, and can determine the success or failure of a cleaning process.

The different models of these recording sheets which have been published are all very limited in the information they can gather. Perhaps the most well-known is the one published by Masschelein-Kleiner in 1981, the use of which has been widespread, with some variations, in Spain. In general, recording sheets include, as basic information, the identification number of the cleaning test, the cleaning system used, the location (with a map to show the exact spot where the test was carried out) and the data obtained. Moreover, other data can also be included, such as the technique used to apply the solvent, the contact time needed to obtain a positive result, etc. A more recent example of a ST recording sheet is the one used in the application software Modular Cleaning Program, designed by Richard Wolbers and Chris Stavroudis (Stavroudis, 2009).
These sheets are not disseminated by conservators. However, given that it is extremely useful material for research purposes, its free dissemination on the Internet would be of great interest. The ideal solution would be the creation of databases which would include stratigraphic information (SU recording sheets) and cleaning test information.

An experimental, non-definitive database has been designed, to find out whether stratigraphic data and cleaning records can, in fact, be interrelated effectively. For this purpose, Microsoft Office Access 2007 was used, designing the simplest possible interface. From the program's main window, access can be gained to "Description of painting", "Stratigraphic study", "Solubility tests" and "Cleaning method" (Guillén Juan, 2009) (Figure 4).

The results of initial tests with this database have been very satisfactory, although it is necessary to achieve a much better relationship between cleaning record and stratigraphic data. There is a model which can be used to attain optimum results when designing this kind of databases: the software programs used by archaeologists to record SU and elaborate stratigraphic diagrams.

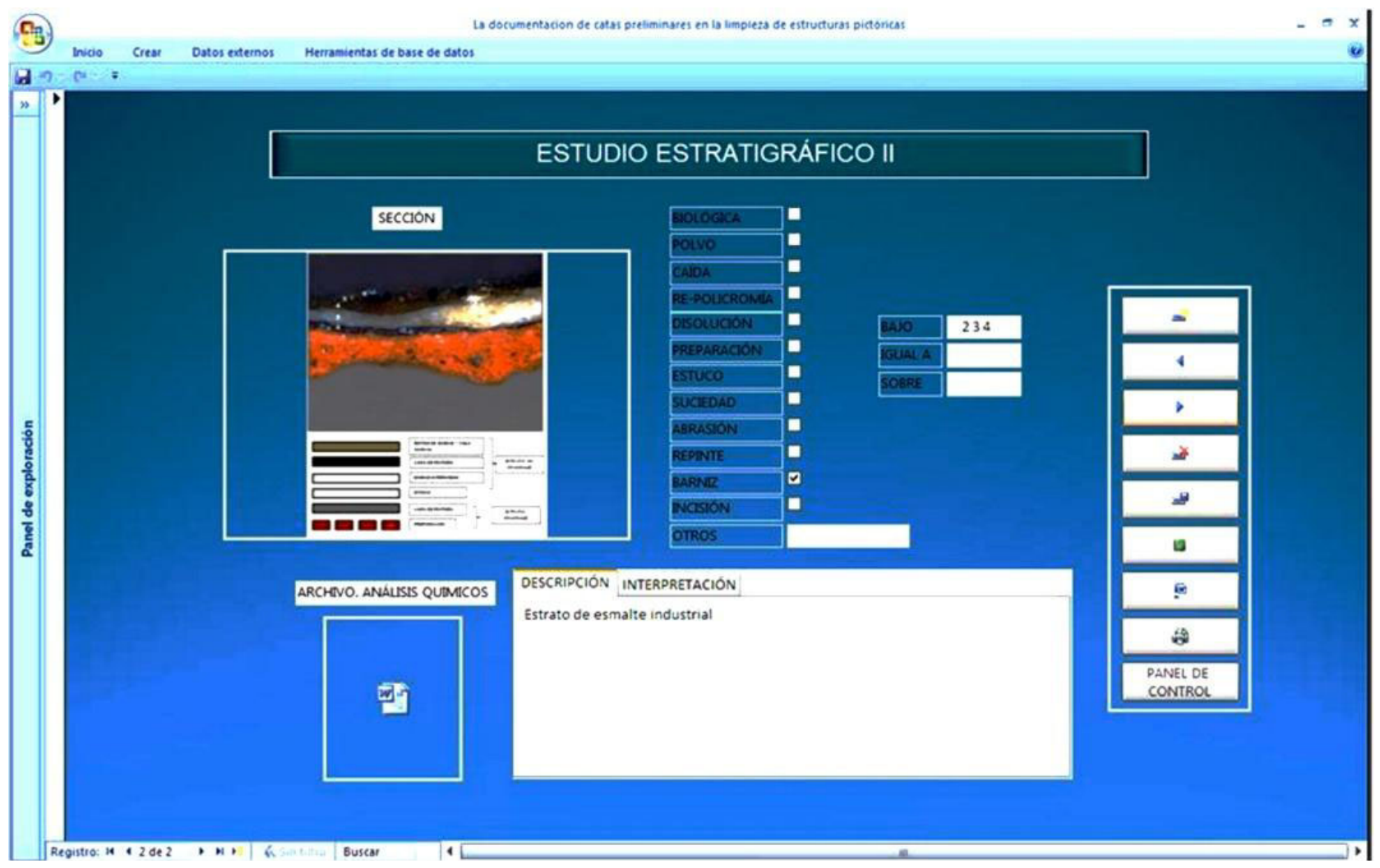

Figure 4. Database designed with Access 2007 to relate stratigraphic data with cleaning records. 


\section{STRATIGRAPHIC DIAGRAMS}

Once the SU documentation is complete, all the relationships they participate in can be shown by means of a stratigraphic diagram or Harris Matrix. This diagram is, basically, a flow diagram which shows all the stratigraphic units and their relationships, whether they involve physical contact (superposition) or not. The units at the top of the diagram are the latest, the most recent, the ones found on the uppermost part of the stratigraphic structure. When one unit is connected to another one by a line, this shows that they are in physical contact (Figure 2).

However, not all relationships are as simple as those of superposition (Figure 5a). In order to record a stratigraphic structure such as that created by non-original deposits on the surface of a painting, we must resort to other relationships: 'SU 1 and 2 are contemporary' or 'SU 1 and 2 are equal'. Two units are considered contemporary when they have been created at approximately the same time and are situated on the same stratigraphic level. In a stratigraphic diagram they are represented as units situated on the same horizontal level (Figure $5 \mathrm{~b}$ ). The relation ' 1 and 2 are equal' refers to units, which originally formed part of a single unit, although now they have been broken up into various separate units (Figure $5 \mathrm{c}$ ). This can occur when, for example, a layer of varnish has only partially been removed. This kind of relationship is shown by means of a pair of horizontal parallel lines connecting both units (Barros García, 2009).

The stratigraphic diagram permits all the SU, which could otherwise only be seen through a great many cross-sections, to be gathered together in one document. Furthermore, it also allows that information to be processed by means of different software programs. There are many programs, both free and otherwise, which despite having been designed for use with archaeological sites, can be used to record strata removed during cleaning. On the Internet, we can find several free programs together with some trial versions which allow a restricted use. Among the latter, Harris Matrix Composer (Traxler and Neubauer, 2008) is worth mentioning.

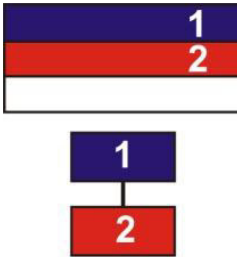

a
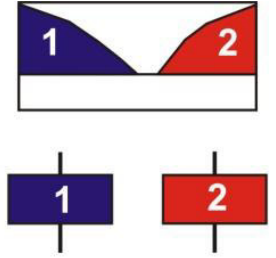

b
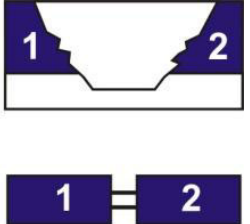

Figure 5. Relationships between two SU: superposition (a), 1 and 2 are contemporary (b); 1 and 2 are equal (c).

Among the free programs, ArchEd (Hundack et al., 2004) and Stratify (Herzog, 2010) are especially noteworthy, although there are also others available such as Tempo (Kähler Holst and Kähler Holst, 2004). The latter is different from the rest as it allows a great variety of relationships to be recorded. The SU recording sheets differ greatly from one software program to another. Stratigraf has a very complete recording sheet which offers the possibility of including graphic documentation (in several formats, such as jpg, bmp or gif). ArchEd and Stratify are free programs but their recording sheets are very basic (Figure 6). Nevertheless, these programs have been used to record the cleaning of several paintings with very good results.

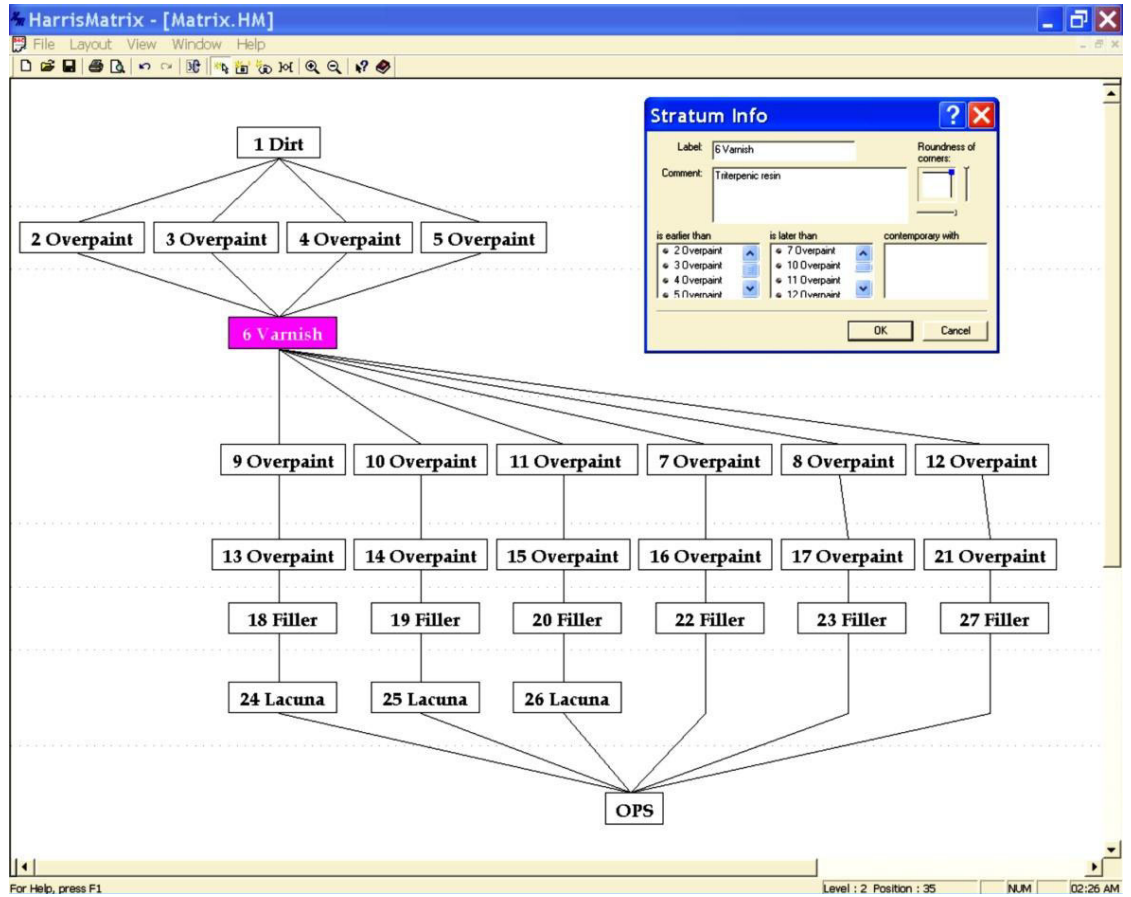

Figure 6. Stratigraphic diagram drawn with ArchEd. 


\section{FURTHER RESEARCH}

Undoubtedly, all the ideas put forward in this paper require further development. The design of databases which integrate ST recording sheets with SU recording sheets is especially important. This would mean a great improvement in recording cleaning and a much better dissemination of the information. The connection between the two sheets is very important because it allows a cleaning test to be linked to the stratum on which it was carried out. A SU recording sheet records the description of the physical characteristics of a stratum (colour, texture, composition, etc.), its location on plan and its relationships with the other units (where the SU is situated within the stratigraphic sequence). This allows all available information concerning a single layer to be gathered together on just one recording sheet, which is why it is logical to link it to the documentation of the cleaning tests carried out on that same layer.

If, in addition, the stratigraphic diagram can be drawn with the same software program, the degree of documentation attained would be similar to that available to archaeologists working on sites. This would be an optimum situation for the proper development of research in the field of cleaning.

However, it is still necessary to take the previous step which consists in standardizing data. It would be necessary to have available a thesaurus, which does not exist yet, in order to accurately describe the SU, their characteristics and their relationships.

\section{CONCLUSIONS}

Archaeological stratigraphy can make a very significant contribution to establishing a methodological base for cleaning pictorial heritage and, in general, for cleaning any polychromed work. In order for this to occur, it is necessary to make a systematic use of the new systems of documentation, especially the SU recording sheets. This is particularly important when cleaning is carried out on works with very complex stratigraphic structures, with multiple non-original deposits from different periods.

There is a need for greater dissemination of the documentation pertinent to cleaning processes and stratigraphic data. The information published is usually insufficient to help develop research in the field of cleaning. Many museums only publish monographs which are not easy to obtain and, only too often, the information concerning cleaning is not sufficiently detailed.

From the design of databases which integrate SU and ST recording sheets, together with stratigraphic diagrams, it is possible to obtain a complete documentation of the cleaning process. From the use of these databases, it is also possible to achieve a very good dissemination of the information, which is essential nowadays in order to advance research.

\section{REFERENCES}

Barker, P., 1977. Techniques of Archaeological Excavation, Batsford, London.

Barros García, J.M., 2004. The use of the Harris Matrix to document the layers removed during the cleaning of painted surfaces. Studies in Conservation, 49(4), pp. 245-258.
Barros García, J.M., 2009. Recording stratigraphic relationships among non-original deposits on a 16th century painting. Journal of Cultural Heritage, 10(3), pp. 338-346.

Barros García, J.M., and Pérez Marín, E. 2010. A new documentation system: SU recording sheets applied to the cleaning of a 15th century painting. In: Cleaning 2010. New insights into the cleaning of paintings. Instituto Universitario de Restauración del Patrimonio (Universitat Politècnica de València) and Smithsonian Institution (Museum Conservation Institute). Valencia, pp. 95-96.

Doglioni, F., 1997. Stratigrafia e restauro. Tra conoscenza e conservazione dell'architettura, Edizioni LINT, Trieste.

Guillén Juan, C.M., 2009. La documentación de catas preliminares en la limpieza de estructuras pictóricas. Master dissertation, Universitat Politècnica de València.

Harris, E.C., 1989. Principles of Archaeological Stratigraphy. Academic Press, London \& San Diego (first edition: 1979).

Herzog, I., 2010. Stratify 1.5. http://www.stratify.org/ Download/Stratify_Manual.pdf (accessed 19 May 2012)

Hundack, C., Mutzel, P., Pouchkarev, I., Reitgruber, B., Schuhmacher, B., Thome, S., 2004. ArchEd. A program for drawing Harris Matrices. https://www.ads.tuwien.ac.at/arched/ (accessed 19 May 2012)

Kähler Holst, K., Kähler Holst, M., 2004. Tempo. http://www.math.ku.dk/ holst/tempo/ (accessed 19 May 2012)

Prisco, G., Guglielmi, A., Mazzeschi, D., Barnaba, C., 2004. Per la storia del restauro della casa dei Vettii in Pompei: una nuova applicazione del diagramma di flusso stratigrafico. Bollettino ICR-Nuova Serie, 8-9, pp. 46-75.

Roskams S., 2001. Excavation. Cambridge University Press, Cambridge.

Stavroudis, C., 2009. The Modular Cleaning Program Version 1.3. http://cool-palimpsest.stanford.edu/byauth/stavroudis $/ \mathrm{mcp} /$ (accessed 19 May 2012).

Traxler, C., Neubauer, W. 2008. The Harris Matrix Composer A New Tool to Manage Archaeological Stratigraphy. In: M. Ioannides, A. Addison, A. Georgopoulos, and L. Kalisperis (eds.). Digital Heritage - Proceedings of the 14th International Conference on Virtual Systems and Multimedia, pp. 13-20.

Vidale, M., Proença de Almeida, N., 2001. Applicazione dei diagrammi di flusso stratigrafici al restauro di manufatti artistici e archeologici. Bolletino ICR-Nuova Serie, 2, pp. 82-103.

Watts, S., Owen-Hughes, H., Laing, A., Staniforth, S., Towle, A., 2002. The Power of the Matrix: the application of archaeological stratigraphy to the interpretation of complex paintings. In: ICOM Committee for Conservation preprints. 13 th triennial meeting, Rio de Janeiro. James \& James, London, pp. $479-485$.

Wolbers, R., 2000. Cleaning painted surfaces. Aqueous methods, Archetype Publications, London. 